\title{
A promoção da inclusão digital e a constituição do Homo oeconomicus accessibilis*
}

\author{
The promotion of digital inclusion and the constitution of \\ Homo œeconomicus accessibilis
}

\section{La promoción de inclusión digital y la constitución del Homo œeconomicus accessibilis}

\author{
CARINE BUEIRA LOUREIRO** \\ MAURA CORCINI LOPES ${ }^{* * *}$
}

\begin{abstract}
$\diamond$
RESUMO - A partir de resultados de pesquisa desenvolvida em uma perspectiva foucaultiana, bem como a partir das ferramentas teórico-metodológicas do discurso e da governamentalidade, o presente artigo problematiza discursos que circulam em programas federais brasileiros sobre inclusão digital na educação. Especificamente, o artigo focaliza a constituição do Homo æeconomicus accessibilis, a partir de três tipos de ações mobilizadas por meio de tais programas, quais sejam: a educação em todos os espaços, a conexão em rede e a disponibilidade para acessar e ser acessado.
\end{abstract}

Palavras-chave - Inclusão digital. Programas governamentais. Governamentalidade.

\begin{abstract}
From the results of a research conducted in a foucauldian perspective, well as from the theoretical and methodological tools of discourse and governmentality, this paper discusses the discourses that circulate in Brazilian federal programs on digital inclusion in education. Specifically, the paper focuses on the creation of Homo ceconomicus accessibilis from three types of actions mobilized through such programs, which are: education in all spaces, the networking and the availability to access and be accessed.
\end{abstract}

Keywords - Digital Inclusion. Government programs. Governmentality.

RESUMEN - A partir de los resultados de una investigación desarrollada en perspectiva foucaultiana, así como desde las herramientas teórico-metodológicas de discurso y gubernamentalidad, el presente artículo problematiza discursos que circulan en programas federales brasileros sobre inclusión digital en educación. Específicamente, el artículo se dedica a presentar la constitución del Homo æeconomicus accessibilis, a partir de tres tipos de acciones generadas por medio de tales programas: la educación en todos los espacios, la conexión en red y la disponibilidad de acceso y de acceder a ella.

Palabras clave - Inclusión digital. Programas de gobiernos. Gubernamentalidad.

* A problematização apresentada neste artigo deriva da Tese de Doutorado intitulada "Disseminação das tecnologias digitais e promoção da inclusão digital na educação: estratégias da governamentalidade eletrônica".

**Doutora em Educação pela Universidade do Vale do Rio dos Sinos (São Leopoldo, RS, Brasil) e professora no Instituto Federal de Educação, Ciência e Tecnologia do Rio Grande do Sul (Bento Gonçalves, RS, Brasil).E-mail: <loureirocarine@gmail.com>.

***Doutora em Educação pela Universidade Federal do Rio Grande do Sul (Porto Alegre, RS, Brasil) e professora na Universidade do Vale do Rio dos Sinos (São Leopoldo, RS, Brasil).E-mail: <maurac@terra.com.br>. 


\section{INTRODUÇÃO}

Inicia-se esta problematização partindo do entendimento de que, na atualidade, falar na promoção da inclusão digital (ID) na educação pública escolarizada parece ter se tornado um imperativo. Com isso, quer se dizer que a inclusão é assumida como algo incontestável, portanto, imposta a todas as formas de vida de maneiras diferenciadas e de acordo com gradientes de participação (LOPES et al., 2010). Mais do que isso, da mesma forma que ocorre com as discussões sobre inclusão escolar, a ID na educação também está na ordem do dia. A promoção da ID na educação é tomada como algo indiscutivelmente bom, necessário, que facilita o processo de ensino e de aprendizagem, auxilia em outros tipos de inclusão, fazse fundamental para que todos tenham oportunidade de acesso aos recursos digitais, melhorem suas chances de empregabilidade e de participação social, etc.

Compreende-se que inserir ferramentas digitais no espaço escolar e proporcionar o acesso a tais recursos são ações tão importantes quanto pensar em como são disseminados os recursos digitais, como é promovida a ID nesses ambientes, que ações são mobilizadas e que tipos de sujeitos são produzidos. Assim, o nosso objetivo neste artigo é tensionar os discursos que circulam nos documentos oficiais referentes a programas federais voltados para a promoção da ID na educação. Na esteira foucaultiana, por discursos entende-se um conjunto de enunciações que permitem olhar e tensionar as práticas e saberes, oriundos de diferentes racionalidades que as pensaram e colocaram em funcionamento, que evocam determinados comportamentos a serem assumidos pelos sujeitos e acabam por operacionalizar estratégias de governamentalidade. Dessa forma, discurso e governamentalidade se constituem nos conceitosferramenta utilizados na analítica desenvolvida ao longo deste artigo.

Para tanto, divide-se este artigo em três partes. A primeira está dedicada à discussão sobre a inclusão digital. Para isso, tensiona-se o tema da inclusão, por se entender que as políticas de inclusão - sejam elas voltadas para a inclusão econômica, digital, por deficiência ou por raça/etnia- estão implicadas umas às outras. E que tanto a inclusão digital quanto a inclusão de qualquer natureza não se constituem em condição de salvação daqueles considerados excluídos. No contexto dessa discussão, apresentam-se as justificativas que levaram à seleção dos documentos referentes ao Programa Nacional de Informática na Educação (Proinfo) e ao Programa Um Computador por Aluno (Prouca) como materiais de pesquisa. Mais especificamente, o documento Diretrizes do Proinfo (PROINFO, 1997) e os materiais Manual do Prouca (PROUCA, 2010a),
Cartilha Projeto UCA (PROUCA, 2010b) e Resolução/ FNDE/CD/n 17 , de 10 de junho de 2010 (PROUCA, 2010c), constituíram o conjunto de materiais a partir dos quais foram desenvolvidas as análises que sustentam a problematização apresentada na segunda parte deste artigo. Ainda nessa primeira parte, desenvolvem-se os conceitos-ferramenta metodológicos do discurso e da governamentalidade, ambos de inspiração Foucaultiana.

Na segunda parte, o objetivo é demonstrar a constituição do tipo de sujeito próprio da Contemporaneidade, que denominamos de Homo oconomicus accessibilis. Para isso, mostra-se, a partir dos materiais analisados, que três tipos de ações são mobilizadas por meio dos programas que promovem a ID na educação, quais sejam: a educação em todos os espaços, a conexão em rede e a disponibilidade para acessar e ser acessado. Compreende-se que é a operacionalização conjunta dessas três ações que atua na produção do Homo æeconomicus accessibilis.

Já na terceira e última parte, apresentam-se as conclusões, procurando estabelecer algumas relações com as discussões desenvolvidas e marcando um posicionamento com relação à promoção da ID na educação pública escolarizada.

\section{A NECESSIDADE DE PROMOVER A INCLUSÃO DIGITAL}

Pensar e problematizar as formas como as práticas inclusivas são operadas se faz importante porque se entende que a inclusão é uma invenção da Modernidade e, como tal, está constantemente sendo modificada, atualizada e ressignificada (LOPES, 2011). A emergência do tema e a necessidade da viabilização de práticas inclusivas podem ser evidenciadas, com maior ênfase, desde o final do século XX, nos discursos políticos, econômicos, educacionais, midiáticos, etc. Mundialmente, esse final de século foi caracterizado pelo capitalismo globalizado e pelo desenvolvimento tecnológico. No Brasil, assistese à retomada da democracia e, principalmente no final dos anos 1990, à mobilização em prol da abertura ao capital estrangeiro e por investimentos crescentes em políticas de diminuição das desigualdades sociais, de expansão da economia e estreitamento dos laços comerciais com as nações mais desenvolvidas. Nesse sentido, países considerados em desenvolvimento, como é o caso do Brasil, começam a integrar grupos ${ }^{1}$ nos quais são intensificados os laços políticos e econômicos por meio das relações de mercado, mais especificamente do comércio e da livre concorrência. A participação nesses grupos se dá sob a égide de compromissos firmados entre cada nação e organismos supranacionais cuja função é regular e estabelecer as condições necessárias para 
a inserção e manutenção de cada um dos integrantes. Em outras palavras, entrar para o grupo e manter-se nele supõe seguir certas regras que regulamentam e controlam as participações, a fim de que seja assegurado certo equilíbrio entre todos os integrantes. Assim, é esperado que problemas sociais, políticos, econômicos, educacionais, de segurança, etc. de um não comprometam o crescimento, o desenvolvimento e a estabilidade econômica dos demais países participantes desses grupos.

Dessa forma, para que seja mantida a ordem interna, "a eficiência da estrutura social, a qualidade de vida da população" (PROINFO, 1997, p. 1), a estabilidade e o desenvolvimento econômico de cada país, cabe ao Estado desenvolver estratégias e pôr em prática mecanismos próprios de regulação e de controle, tanto da população como também de cada indivíduo em particular, procurando evitar desvios na conduta das pessoas em geral. Para tanto, é imprescindível dispor de saberes e mecanismos que lhe possibilitem prever com antecedência adequada tais perturbações, a fim de que uma possível desordem possa ser antecipadamente gerenciada e a ordem interna seja mantida e garantida.

Manter a ordem interna implica a necessidade de fazer investimentos na obtenção de dados que possibilitem mapear os sujeitos considerados em situação de risco social. Isso também explica os altos investimentos feitos pelo Estado brasileiro na segunda metade da década de 1990, em estudos estatísticos que levam à criação de políticas de assistência social e educacional. A estatística é a ciência utilizada pelo Estado, desde o final do século XVI, e que adquire amplitude no século XVII, possibilitando todo um conjunto de análises e saberes acerca dos dados, das dimensões e do poder do próprio Estado em relação à condução da população (FOUCAULT, 2008).

Em "situação de risco social" é como são caracterizados os indivíduos que não possuem nenhum tipo de vínculo seja de trabalho, educacional ou de assistência social - que permita ao Estado ter conhecimento sobre a sua existência e regular as suas condutas. Nesse sentido, as políticas que visam à promoção da ID na educação não ficam alheias à necessidade de estabelecer vínculos entre a população considerada em situação de risco social e o Estado. Por isso, torna-se fundamental "utilizar todos os recursos disponíveis e adequados à preparação, reprodução, transmissão e recepção de dados e informações" (PRONINFE, 1989, p. 20) sobre a população. Assim, investir em programas que fomentam a ID na educação pode se constituir em uma das formas de ampliação das possibilidades de captura dos sujeitos e de extração de informações sobre eles.

A ênfase dada à coleta de dados e informações torna possível afirmar que, na atualidade, considerando a amplitude e a variedade de políticas de inclusão, os altos investimentos em censos populacionais, educacionais, de assistência social, etc., é cada vez menor o número de indivíduos que não são reconhecidos pelo Estado. No entanto, não basta conhecer a população - não é suficiente que todos sejam reconhecidos pelos levantamentos demográficos -, é preciso contar com políticas de assistência social, de inclusão educacional, social e digital que possibilitem a participação de todos, mesmo que tal participação seja em diferentes níveis.

Com relação aos diferentes níveis de participação, citam-se as ações viabilizadas por meio do PROINFO, que visam à "universalização do uso da tecnologia" (PROINFO, 1997, p. 1) no sistema público de ensino; e por meio do PROUCA, cujo investimento está na promoção da "inclusão digital de familiares e da comunidade em geral" (PROUCA, 2010, p. 1) por meio da distribuição de computadores individuais portáteis aos alunos do sistema público de ensino básico. Dessa forma, considerando que, por meio dos programas de inclusão, as condições de acesso sejam dadas a quase todos, "não é possível afirmar que aqueles sujeitos que participam [...] de programas de assistência do Governo Federal [...] estejam excluídos" (LOPES; RECH, 2013, p. 212). No entanto, se o foco estiver, por exemplo, nas políticas de ID, diferentes alunos do sistema público de ensino podem ter diversos níveis de participação no mundo digital.

Nesse contexto, os incluídos são "os que integram a sociedade em diferentes níveis de participação ou gradientes de inclusão" (LOPES et al., 2010, p. 5) e, por esse aspecto, torna-se difícil identificar quem são os incluídos e quem são os excluídos. Isso porque, a todo momento, qualquer sujeito pode estar, ao mesmo tempo, incluído ou excluído de determinados espaços, práticas, ações, políticas, o que configura tanto a inclusão quanto a exclusão como invenções deste mundo (LOPES et al., 2010). Para Lopes e Fabris (2013, p. 74), “in/ excluídos passa a ser um conceito que abrange tipos humanos diversos que vivem sob variadas condições, mas que carregam consigo uma história de discriminação negativa". Ainda conforme as autoras, tal conceito surge "para mostrar que, embora muitos estejam incluídos nas estatísticas e em alguns espaços físicos, boa parcela dos indivíduos ainda sofre com as práticas de inclusão excludentes". Assim, o conceito de in/exclusão abarca os múltiplos sentidos que circulam entre a integração e a inclusão, como também envolve o escorregadio e múltiplo conceito de exclusão (LOPES, FABRIS, 2013).

Essa necessidade de incluir todos, mesmo que de acordo com diferentes gradientes de participação, insere-se na racionalidade política e econômica da lógica neoliberal de direcionamento das condutas, cuja centralidade consiste na construção de uma sociedade regida pela concorrência e que tem o mercado como única 
forma social válida; mais especificamente, o principal objetivo do projeto neoliberal é "disseminar o mercado globalmente" (LAGASNERIE, 2013, p. 47). Essa lógica articula, de uma forma jamais vista, a política, o direito e a economia - de maneira que estes atuem conjuntamente a favor do mercado -, modifica a organização social especialmente as relações entre o individual e o coletivo (LAGASNERIE, 2013) - e produz a condução dos comportamentos individuais e coletivos, de modo a responsabilizar cada um e, ao mesmo tempo, a todos pelo desenvolvimento do país. Dessa forma, importa para essa racionalidade que todos sejam convocados a melhorar os índices de educação, saúde, segurança, etc., procurando diminuir a dependência da população em relação ao Estado e aumentar o nível de participação de cada um.

Ao considerar-se a necessidade de obter dados e informações que permitam mapear a população e incluir todos na lógica do neoliberalismo, compreende-se que as ações de inclusão operam tanto por meio de práticas de governamento do Estado sobre a população que se quer governar quanto por meio das práticas de subjetivação (LOPES, 2011). Com isso, observa-se que as políticas de inclusão operam por meio de ações externas, organizando o campo de ação dos sujeitos com vistas a atender aos modos de viver produzidos por um tipo de racionalidade - no caso, a racionalidade neoliberal. Além de atuarem também sobre esses sujeitos para que eles conduzam a si mesmos e orientem os outros a se comportarem conforme determinadas formas de ser, de se relacionar, trabalhar, competir, comunicar, etc., próprias dessa mesma racionalidade. Nesse contexto, as práticas de inclusão operam produzindo ações externas de direcionamento das condutas que se constituem nas práticas de governamento, enquanto as práticas de subjetivação atuam definindo formas de ser e de se comportar assumidas pelos sujeitos. As práticas de subjetivação forjadas em um éthos ou em uma atitude de Modernidade que escrutina os corpos e os posiciona dentro de uma cadeia normativa e de posições de sujeitos se deslocam e se constituem contemporaneamente em um éthos de extrema liberdade de escolha e de formas de ser. Isso significa que o sujeito moderno - marcado pela disciplina, docilidade, autonomia, binarismos e obediência pastoral- esmaece e fortalece o sujeito contemporâneo - individualista, empreendedor, múltiplo, competitivo, empresário de si mesmo, ativo, independente, gestor, etc. Enfim, é na imanência das práticas de governamento com as práticas de subjetivação que se dá a formação da governamentalidade.

Assim, se investir em políticas de inclusão pressupõe garantir que todos aqueles que antes não tinham acesso, agora, passem a ter condições, mesmo que mínimas, de consumir, competir, participar, investir em políticas de ID. Para Kampff (2009), isso significa possibilitar a participação plena na vida em sociedade. Acrescenta-se ainda que, no século XXI, estar incluído digitalmente não somente amplia as possibilidades de participação, mas representa condição mínima para viver em uma sociedade que interage em forma de rede. Para tanto, torna-se necessário que, além de incluídos digitais, todos tenham condições de estar disponíveis para acessar e para serem acessados. Nesse sentido, se essa condição deve ser ofertada a todos, então cabe ao Estado promover meios para que todos tenham acesso às TDs.

A necessidade de que o Estado proporcione à maior parcela possível da população condições de acesso aos recursos digitais talvez seja uma das justificativas utilizadas para que o Proinfo - programa que vem sendo implementado desde 1997 e cujo objetivo era a criação de laboratórios de informática em escolas públicas de educação básica e não a promoção da ID - passe a integrar o conjunto de políticas de ID. Mesmo que o programa não tenha sido criado com essa finalidade. As discussões sobre o tema, bem como a própria propagação do termo inclusão digital, emergem no Brasil, no final de século XX e no início do século XXI. Mais especificamente, as discussões acerca da ID surgem atreladas à consolidação da internet comercial e à ampliação da sua utilização fora dos espaços acadêmicos. Na atualidade, é possível observar três diferentes ênfases atribuídas à concepção do que vem a ser a inclusão digital (CORREA, 2007). Uma dessas ênfases, e talvez a que mais esteja sendo refutada, diz respeito à necessidade de prover, equitativamente, oportunidades de acesso às pessoas pertencentes às camadas economicamente menos favorecidas da população. Outra forma de entender a ID enfatiza não só a necessidade de prover o acesso, mas também a importância de capacitar os sujeitos para que o uso das TDs se torne algo naturalizado nos grupos mais carentes da população. Por fim, um terceiro grupo enfatiza a importância de mesclar acesso e uso das TDs como forma de promover a ID.

Diante da necessidade de o Estado brasileiro promover a ID pelo viés da educação pública institucionalizada, em 2010, como um programa que se vincula diretamente ao Proinfo, foi criado o Prouca, com o objetivo de "promover a inclusão digital pedagógica de alunos e professores" (PROUCA, 2010a, s/p.). Nesse aspecto, afirma-se que não é objetivo deste artigo avaliar os programas Proinfo e Prouca enquanto sua potencialidade política, verificar como eles estão sendo operacionalizadas nas escolas, nem tampouco avaliar seus resultados. Até porque consideram-se, alguns deles, muito positivos para o contexto da educação e da interação entre os sujeitos da educação. A intenção aqui é olhar para os documentos oficiais, emitidos pelo governo federal, referentes ao Proinfo e ao Prouca, e tensionar os discursos que são mobilizados por meio desses programas 
e para os saberes e práticas que são produzidos por meio de tais discursos.

Cabe ainda acrescentar que o Prouca é uma das ações viabilizadas por meio da política de governo eletrônico, que

atua por meio da inclusão digital para que o cidadão exerça a sua participação política na sociedade do conhecimento. As iniciativas nessa área visam garantir a disseminação e o uso das tecnologias da informação e comunicação orientadas ao desenvolvimento social, econômico, político, cultural, ambiental e tecnológico, centrados nas pessoas, em especial nas comunidades e segmentos excluídos (BRASIL, 2012; s/p., grifos das autoras).

A educação escolarizada parece se constituir em um lócus produtivo para a política de governo eletrônico, no qual a disseminação das TDs e a promoção da ID são investimentos fundamentais. Isso reforça a necessidade de o Estado investir em políticas que garantam a todos as condições para que sejam incluídos digitais. Para Medeiros (2004), as TDs têm potencial para construir uma nova relação entre o governo e a população, e isso pode se dar por meio de uma maior participação dos indivíduos ao utilizar os recursos digitais. Importa acrescentar que, em 2003, no âmbito do governo eletrônico, foi instituído o Comitê de Inclusão Digital, e a ID tornou-se uma das diretrizes estratégicas dessa política. No entanto, embora a ID seja uma condição necessária para o sujeito interagir numa sociedade cada vez mais desenvolvida tecnologicamente, somente a capacitação nessa área não é suficiente. É preciso que seja proporcionado o acesso da população às redes de comunicação, $\mathrm{o}$ que faz com que este se torne fator primordial.

Assim, entende-se que os discursos articulados por meio da promoção da ID na educação operam produzindo a constituição de sujeitos afinados aos modos de ser e de viver característicos da Contemporaneidade. Amparados estes em algumas ações mobilizadas por meio das práticas de disseminação das TDs na educação - distribuição de computadores, capacitação de recursos humanos para o uso das TDs e produção do desejo pela internet. Esses sujeitos devem estar empenhados em desenvolver características como criatividade, participação, colaboração, iniciativa e devem ser capazes de "se comunicar, conviver e dialogar num mundo interativo e interdependente" (PROINFO, 1997, p. 3). Para tanto, nos discursos mobilizados por meio dos programas voltados para a ID na educação, percebe-se: o fomento à educação em todos os espaços, a conexão em rede e a disponibilidade para o sujeito acessar e ser acessado; investimentos na produção do Homo oconomicus accessibilis; um sujeito que, além de ser um empresário de si mesmo, também deve ter condições de acessar e estar disponível para ser acessado.

\section{A CONSTITUIÇÃo DO HOMO GCONOMICUS ACCESSIBILIS}

Conforme mencionada acima, a constituição do Homo oconomicus accessibilis está apoiada no engendramento de três ações, mobilizadas por meio da promoção da ID na educação, que são a aprendizagem em todos os espaços, a conexão em rede e a disponibilidade do sujeito para acessar e ser acessado. Para que se explique como se dá a constituição de tal tipo de sujeito, recorre-se primeiramente à noção de Homo æeconomicus desenvolvida por Michel Foucault na aula de 14 de março de 1979, no Curso Nascimento da Biopolítica. Compreende-se que é a partir dos investimentos na promoção da ID na educação escolarizada que se dá a constituição do que se pode classificar como uma subespécie do Homo ceconomicus, qual seja o Homo oeconomicus accessibilis. Na sequência, discutem-se as ênfases que se entende como características da educação escolarizada moderna e contemporânea, com a intenção de demonstrar como se percebe a escola contemporânea comprometida com a constituição desse outro tipo de sujeito.

Foucault (2008b), ao problematizar aspectos do neoliberalismo americano, demonstra que o tipo de sujeito de interesse dessa racionalidade política é o Homo oeconomicus, que na concepção clássica era o homem da troca e na concepção neoliberal passa a ser o empresário de si mesmo. No centro dessa racionalidade está a Teoria do Capital Humano, desenvolvida pela Escola de Chicago, berço do neoliberalismo americano, e que tem como um dos seus principais expoentes Theodore Schultz. O filósofo explica também que, conforme essa teoria, "uma renda é simplesmente o produto ou o rendimento de um capital" (FOUCAULT, 2008b, p. 308). Capital, cuja renda é o salário, "é o conjunto de todos os fatores físicos e psicológicos que tornam uma pessoa capaz de ganhar este ou aquele salário" (FOUCAULT, 2008b, p. 308). O indivíduo não pode ser separado da sua capacidade para ganhar o salário; por isso, a importância de que o indivíduo aprenda e assuma a necessidade de fazer investimentos em si mesmo ao longo da vida. Nessa esteira, entendese que a educação escolarizada, na Contemporaneidade, dada a sua relação de imanência com a sociedade, vê-se comprometida com a constituição desse tipo de sujeito cuja habilidade de fazer investimentos em si mesmo deve ser desenvolvida. Assim, acredita-se que tal ênfase acaba por provocar certo deslocamento que diferencia as funções que eram atribuídas à escola moderna daquelas que são atribuídas à escola contemporânea.

A escola moderna, além do seu principal objetivo que era o disciplinamento dos indivíduos, enfocava também o ensino de conhecimentos específicos de áreas como Matemática, Língua Portuguesa, História, Geografia, 
Biologia, Química, Física, etc. Na Contemporaneidade, a escola não abandona as suas "funções modernas", no entanto propaga a ideia de que "o conhecimento especializado está tendo uma vida média cada vez menor" (PROINFO, 1997, p. 2) e há necessidade de "constantes aperfeiçoamentos" (PROINFO, 1997, p. 2) e novas experiências para modificar algumas de suas funções. Ressalta-se que o disciplinamento e o processo de ensino e de aprendizagem de conteúdos de áreas específicas já não são mais os enfoques atribuídos à educação escolarizada na atualidade. A ênfase parece estar direcionada para a aprendizagem de outras formas de comportamentos isto é, formas de conceber a si mesmo, formas de ser, de se relacionar, de se comunicar, de consumir, competir, interagir, etc., conforme mencionado na seção anterior.

Para que esse tipo de comportamento seja desenvolvido, a capacidade do sujeito de se manter em contínuo processo de aprendizagem é um dos seus principais motores. Ele precisa assumir a responsabilidade de fazer investimentos constantes em si mesmo, de se comportar como um aprendiz permanente e de entender a sua vida como um empreendimento constante. Desenvolver a capacidade de ser um aprendiz por toda a vida é de fundamental importância por dois motivos. Primeiro, para que os sujeitos aprendam a fazer investimentos em si mesmos e com isso aumentarem as suas condições de empregabilidade. Segundo, espera-se que, assumindo tal responsabilidade, o sujeito também se torne responsável pela condução das suas condutas e dos outros, desonerando, ou pelo menos minimizando paulatinamente, o Estado de determinadas obrigações para com a população.

A capacidade de se manter em contínuo processo de aprendizagem, referenciada por Sthepen Ball (2013) como "Aprendizagem ao Longo da Vida" (ALV), pode ser entendida como uma das principais formas de investimento em capital humano mobilizadas na atualidade, tanto por meio de diretrizes de organismos supranacionais e de políticas de assistência social quanto por meio de políticas educacionais (BALL, 2013). Embora a discussão desenvolvida por Ball (2013) esteja embasada em uma análise de documentos referentes a diretrizes educacionais de países europeus e em uma declaração da Unesco, é possível observar uma estreita relação entre as percepções referentes àqueles países e as políticas educacionais brasileiras. Essa aproximação reforça a ideia de que se está imerso em um processo de globalização que faz com que os discursos acerca das políticas educacionais desenvolvidas em outros continentes demonstrem uma ligação inextrincável com aqueles proliferados no Brasil. Ball (2013, p. 145) explica ainda que "no cerne desse fervilhante discurso sobre o aprendiz ao longo da vida está o indivíduo empreendedor". Com relação às suas análises, o pesquisador afirma que "o que é produzido nesses documentos e o que é tema das políticas que deles provêm não é mais que um novo tipo de pessoa e uma nova ética de personalidade, no contexto da aprendizagem ao longo da vida" (BALL, 2013, p. 145).

Com relação à centralidade atribuída à formação de sujeitos aprendentes, Noguera-Ramírez (2011) salienta que a virada do século XIX para o século XX parece ter sido marcada pela passagem do ensino e da instrução para a aprendizagem, e utiliza a denominação Homo discentis (NOGUERA-RAMÍREZ, 2011) para esse indivíduo que tem como principais características a "responsabilidade pessoal e a autogestão dos próprios riscos e do destino" (NOGUERA-RAMÍREZ, 2011, p. 16). Percebe-se que se está diante de uma nova forma de subjetivação que produz um comportamento de aprendiz permanente, ou seja, "um Homo aprendiz permanente, definido por sua condição de ser um aprendiz ao longo da vida, ou melhor, um Homo que, para ser tal, deve aprender permanentemente" (NOGUERA-RAMÍREZ, 2011, p. 16-17).

Nessa linha da educação em todos os espaços e que fomenta a aprendizagem ao longo da vida, Valente (2008, p. 24), um importante pesquisador da área de tecnologias digitais e educação, explica que, na atualidade, “a questão fundamental do processo de ensino-aprendizagem é saber como prover a informação de modo que ela possa ser interpretada pelo aprendiz e que ações ele deve realizar para que essa informação seja convertida em conhecimento". Para esse pesquisador,

\begin{abstract}
A mudança pedagógica que todos almejam é a passagem de uma Educação totalmente baseada na transmissão da informação, na instrução, para a criação de ambientes de aprendizagem nos quais o aluno realiza atividades e constrói o seu conhecimento. Essa mudança acaba repercutindo em alterações na escola como um todo: na sala de aula, no papel do professor e dos alunos e na relação com o conhecimento (VALENTE, 1999, p. 31).
\end{abstract}

Segundo Valente (2008, 1999), proporcionar ao aluno o acesso a dados e a informações talvez seja o suficiente para que conhecimentos novos sejam produzidos e, nessa linha, a qualidade do que será aprendido, assim como o conhecimento produzido, irá depender da forma como serão feitos o processamento, a interpretação e as relações que serão estabelecidas a partir das informações acessadas. Essa nova concepção de ensino e de aprendizagem vem em substituição à concepção chamada de "tradicional" pelas linhas pedagógicas que condenam o processo no qual o professor ensina ao aluno determinados conhecimentos específicos com ênfase na transmissão. Para esse tipo de fundamentação pedagógica, a criação de ambientes de aprendizagem é fundamental e as políticas voltadas para a disseminação das TDs e para a promoção da ID na 
educação, desde o década de 1980, quando foram feitos os primeiros investimentos por meio do Projeto Educom, parecem afinar-se a tal concepção. Reforçando essa ideia, em uma publicação relacionada ao Proinfo (1997), intitulada Aprendizes do futuro: as inovações começaram, é enfatizada a importância de que os alunos sejam capazes de "estabelecer relações entre as informações e gerar conhecimento" (FAGUNDES; SATO; MAÇADA, 1999, p. 24). As autoras responsáveis pela elaboração desse material complementam que a prioridade é desenvolver a "capacidade de continuar aprendendo" (FAGUNDES; SATO; MAÇADA, 1999, p. 24).

Para Richard Sennett (2012), assim como para Stephen Ball (2013), desenvolver a capacidade de aprender coisas novas e de se manter em constante processo de aprendizagem torna-se uma das condições para o indivíduo se tornar empregável e manter-se em condições de empregabilidade na atualidade. Saraiva e Veiga-Neto (2009), ao problematizarem a educação contemporânea, explicam que, especialmente no contexto de algumas pedagogias - como é o caso daquelas que enfatizam o aprender a aprender -, "o aprender a aprender significaria tornar-se empresário de si, colocando-se num processo de gestão [...] do capital humano" (SARAIVA; VEIGANETO, 2009, p. 199, grifos dos autores). Nesse contexto, para potencializar tal capital, caberia à escola ensinar o indivíduo a aumentar, a intensificar e a gerir o seu próprio capital humano. Portanto, entende-se que os discursos viabilizados por meio da promoção da ID na educação fortalecem essa tendência pedagógica centrada no aprender a aprender e também funcionam como estratégias que potencializam os investimentos em capital humano.

$\mathrm{Na}$ sequência, com a intenção de dar visibilidade às discussões e à afirmação que se fez inicialmente - a de que se percebe a constituição de um outro tipo de sujeito, por meio dos discursos mobilizados nos documentos relativos aos programas que fomentam a ID na educação - apresentam-se os excertos selecionados a partir de uma das perguntas que fazem parte do material de pesquisa e que intitula o quadro a seguir.

Quadro 1 - De que maneira é vista a tecnologia aplicada à educação?

\begin{tabular}{|c|c|}
\hline Proinfo & Prouca \\
\hline $\begin{array}{l}\text { O programa tem como proposta melhorar a qualidade do processo } \\
\text { ensino-aprendizagem (PROINFO, 1997, p. xx). } \\
\text { [...] usar o computador como prótese de inteligência e ferramenta de } \\
\text { investigação, comunicação, construção, representação, verificação, } \\
\text { análise, divulgação e produção de conhecimento. E o lócus ideal } \\
\text { para deflagrar um processo dessa natureza é o sistema educacional } \\
\text { (PROINFO, 1997, p. xx, grifos das autoras). } \\
\text { As novas tecnologias da informação devem ser aproveitadas pela } \\
\text { educação para preparar o novo cidadão, aquele que deverá colaborar } \\
\text { na criação de um novo modelo de sociedade (PROINFO, 1997, p. xx, } \\
\text { grifos das autoras). } \\
\text { As modernas tecnologias de informação e comunicação tornam } \\
\text { crescentes as tendências de surgimento de uma sociedade planetária. } \\
\text { Isto exige seres sociais capazes de se comunicar, conviver e dialogar } \\
\text { num mundo interativo e interdependente. Seres que entendem a } \\
\text { importância de subordinar o uso da tecnologia à dignificação da vida } \\
\text { humana, frutos de uma educação voltada para a democracia e amparada } \\
\text { em valores, tais como tolerância, respeito e solidariedade (PROINFO, } \\
\text { 1997, p. xx, grifos das autoras). }\end{array}$ & 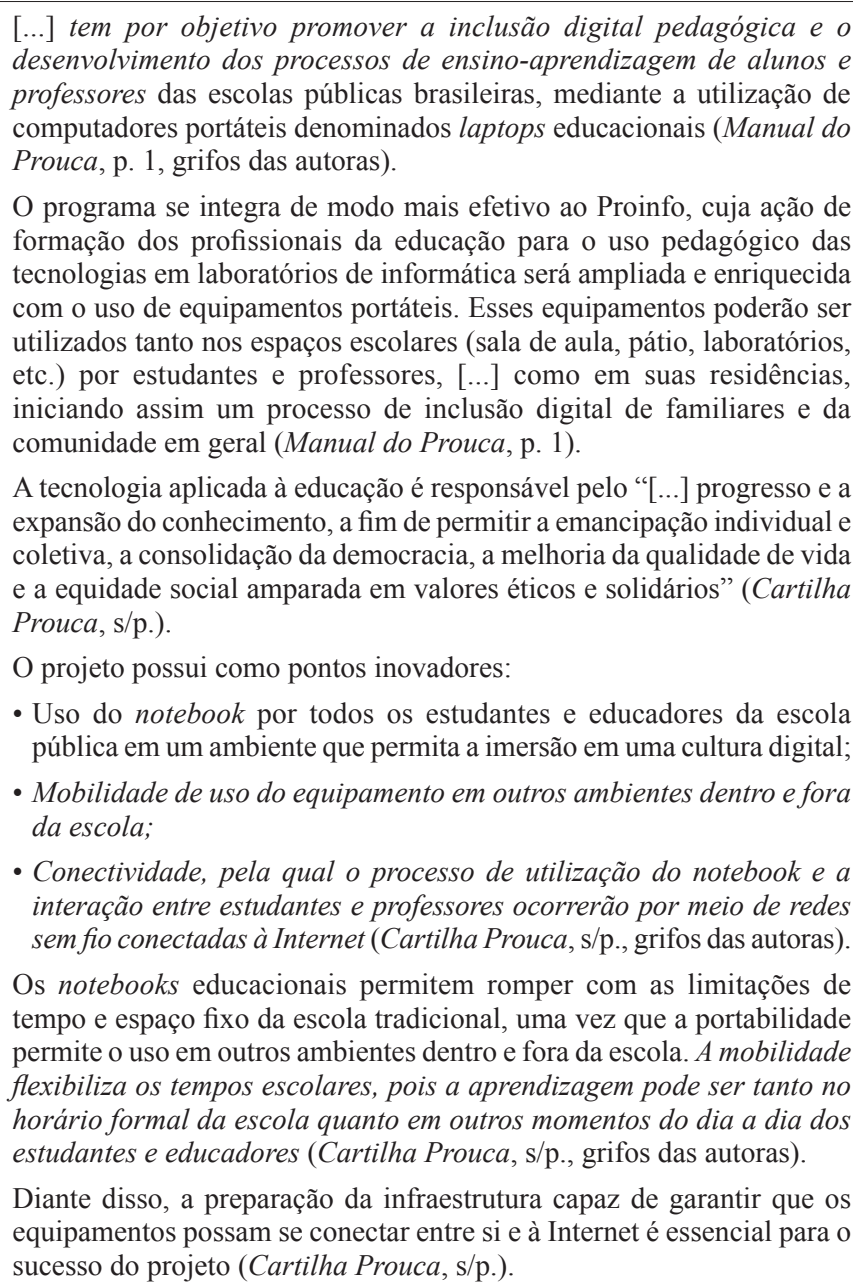 \\
\hline
\end{tabular}


O "novo cidadão" (PROINFO, 1997, 3) a ser constituído por meio dos investimentos na promoção da ID na educação, "aquele que deverá colaborar na criação de um novo modelo de sociedade" (PROINFO, 1997, 3), é alguém participativo, criativo, colaborativo, que tem iniciativa, é capaz de "se comunicar, conviver e dialogar num mundo interativo e interdependente" (PROINFO, 1997, p. 3). Além disso, quando o Proinfo, (1997) propõe a utilização de computadores na educação como forma de "melhorar a qualidade do processo ensino-aprendizagem" (PROINFO, 1997, p. 3), compreende-se que tal investimento, mais do que alavancar o processo de ensino e de aprendizagem, prioriza a criação de espaços nos quais o uso das TDs propicia a alunos e professores o acesso à informação. Nessa linha, na série de cadernos da coleção Informática para a mudança na educação, a partir de diferentes relatos de experiências e artigos relacionados à pedagogia de projetos, é anunciado que, nesse tipo de metodologia, "a prioridade não é o conteúdo em si, formal e descontextualizado. A proposta é aprender conteúdos, por meio de procedimentos que desenvolvam a própria capacidade de continuar aprendendo" (FAGUNDES; SATO; MAÇADA, 1999, p. 24).

Barreto (2012), fundamentada (é mulher?) em outra perspectiva teórica, mais especificamente na teoria da análise crítica do discurso, demonstra que, dada a centralidade atribuída à aprendizagem, está se vivendo um processo de "recontextualização educacional das TIC",(no original está sem "s"?) e tal processo "precisa dar conta dos pressupostos e dos implícitos das políticas que o têm sustentado". Acrescenta que há, nesse sentido, uma simplificação do processo de formação e de trabalho docente e, como consequência dessa situação, a ressignificação de ensinar e aprender (BARRETO, 2012, p. 991). "Ensinar (ensino) é um termo cada vez menos presente, ao passo que aprender (aprendizagem) é uma escolha lexical cada vez mais recorrente" (BARRETO, 2012, p. 991). Ao se perceber que a aprendizagem é enfatizada em contraposição ao esmaecimento do ensino, observam-se alterações nas funções atribuídas a alunos e professores. Antes - nos primeiros movimentos de disseminação das TDs na educação -, o papel do professor era "o de facilitador, supervisor, consultor do aluno" (VALENTE, 1999b, p. 40). Já a ID na educação, ao objetivar "promover a inclusão digital pedagógica de alunos e professores" (PROUCA, 2010, p. xx), além de equiparar as funções docentes e discentes, difunde a ideia de que o professor se torne um "modelo de aprendiz" (VALENTE, 1999b, p. 40).

Dessa forma, atesta-se que a promoção da inclusão digital (pedagógica), parece ir além da expansão do uso das TDs aos escolares, pois, mais do que o acesso aos recursos digitais e à internet, promover a ID, nesse caso, significa disponibilizar a cada professor e a cada aluno a mobilidade individual no que diz respeito ao uso da tecnologia e ao acesso à internet. Assim, a ideia difundida no Prouca reforça o princípio da educação em todos os espaços, a possibilidade da conexão em rede e a disponibilidade para o sujeito acessar e ser acessado em qualquer local e horário. Por meio da promoção da ID na educação, parecem se consolidar as condições mínimas necessárias, embora não suficientes, para que cada vez mais indivíduos estejam aptos a participar dos modos de vida conduzidos pela racionalidade neoliberal.

A ampliação do tempo e dos lugares para o desenvolvimento do processo educativo, conforme é propagado pelo Prouca ao enunciar que estudantes e educadores podem "aprender" tanto nos horários formais de estudo/trabalho na escola quanto fora dela, implica não só constituição de outros ambientes de aprendizagem, para além da instituição escolar, mas também a produção de outro tipo de sujeito. Este, muito mais voltado para formas de se comportar e de ser afinadas ao empresariamento de si e para a necessidade de se manter conectado. Nesse sentido, a mobilidade proporcionada pelos laptops individuais parece ser o suficiente para que não só a escola seja um espaço para que a educação se desenvolva, mas também a casa, a empresa, as praças, os shoppings, etc. sejam transformados em espaços desse tipo. Porém, somente dispor do equipamento não é suficiente -, livros, revistas, jornais, materiais impressos em geral também proporcionam mobilidade e a possibilidade de educação em diferentes espaços -, é preciso estar conectado, manter-se em interação com os demais e ter disponibilidade para acessar outros espaços e pessoas a qualquer momento. Da mesma forma, também se faz necessário estar disponível para ser acessado a qualquer hora e em qualquer lugar. Assim, é difundida a ideia de que não há limites para o desenvolvimento da aprendizagem, pois a educação pode acontecer em qualquer espaço. Cabe ao sujeito aproveitar as oportunidades concedidas pelo Estado, empenhar-se para fazer os investimentos em si mesmo e mudar a sua condição econômica e social.

Nessa linha, a promoção da ID na educação reforça a produção de outras formas de comportamento. Já que enfoca a ideia de que a utilização de computadores portáteis individuais proporciona o rompimento das "limitações de tempo e de espaço fixo da escola tradicional" (PROUCA, 2010a, s/p.) e de que a "conectividade, pela qual (acho que essa parte precisa ser cortada para a frase não ficar truncada) "o processo de utilização do notebook e a interação entre estudantes e professores ocorrerão por meio de redes sem fio conectadas à Internet" (PROUCA, 2010a, s/p.). Já para Sibilia, 
em vez da prisão - com suas grades, seus cadeados, suas normas estritas e punições severas -, teríamos como modelo universal, cada vez mais, uma rede eletrônica aberta e sem fios, à qual cada um se conecta por livre e espontânea vontade: apenas onde, quando e se quiser. Por isso, ali onde imperavam as normas ríspidas do confinamento [...] agora se estendem as tramas atraentes da conexão, que opera [...] enfeitiçando os consumidores contemporâneos com suas incontáveis delícias midiáticas (2013, p. 174, grifos da autora).

$\mathrm{Na}$ mesma direção, importa aqui deixar evidente que, embora se perceba enfatizada a necessidade a conexão em rede e a disponibilidade para acessar e ser acessado favoreçam o desenvolvimento da educação em todos os espaços, não se entende que a escola deixe de ser um lugar privilegiado para que a educação se desenvolva. Diferentemente disso, na atualidade, dada a proliferação de políticas de inclusão voltadas para a educação escolarizada e que objetivam trazer todos para os limites internos dessa instituição, a escola se torna cada vez mais potente e fundamental. Todavia, parece que, especialmente como o incentivo à promoção da ID na educação, algumas modificações podem ser percebidas, dentre elas, a noção de que a escola não é o único local no qual a educação pode se desenvolver. Talvez mais importante do que aprender conteúdos específicos seja aprender a participar das formas de vida instituídas na Contemporaneidade, para as quais importa que seja cada vez maior o número de sujeitos autônomos, responsáveis pelo seu sustento, empresários de si mesmos, parceiros do Estado, etc. O entrelaçamento das ações que fomentam a educação em todos os espaços, a conexão em rede e a disponibilidade para acessar e ser acessado criam as condições de possibilidade para a constituição desse tipo de sujeito.

De toda forma, cabe pontuar que, embora a conexão em rede e a disponibilidade para acessar e ser acessado, incentivadas por meio da promoção da ID na educação, potencializem o desenvolvimento da educação em todos os espaços, não apagam a função disciplinar atribuída à maquinaria escolar desde o seu surgimento, no século XVI. Talvez o que ocorra seja um esmaecimento dessa função em detrimento da ênfase dada a outras atribuições. Salienta-se que a propagação da noção de educação em todos os espaços, que está amparada na conexão em rede e na disponibilidade para acessar e ser acessado, não rompe com as "limitações de tempo e de espaço fixo da escola tradicional” (PROUCA, 2010a, s/p.). O entrelaçamento dessas três ações pode proporcionar a ampliação do espaço e do tempo para além da limitação espacial e da hierarquização temporal da instituição escolar. No entanto, tanto alunos quanto professores continuam ligados a um sistema que exige não só a presença física, mas também a pontualidade e a comprovação da assiduidade. Além disso, a educação escolarizada, independentemente da inserção do uso das TDs, permanece vinculada a currículos formatados conforme uma organização que é disciplinar.

Colocando de outra maneira, é importante se atentar também que a conexão em rede e a disponibilidade para acessar e ser acessado ampliam as possibilidades de controle e de regulação. Essas possibilidades são ampliadas porque a necessidade de estar conectado e de poder acessar e ser acessado a qualquer momento propicia que todos possam controlar a todos. Nessa linha, a regulação também é expandida, pois cada um deve regular a si mesmo, mantendo-se conectado - para que possa acessar e esteja acessível -, fazendo-se presente para os demais, ao mesmo tempo em que regula a presença dos outros na rede. Assim, a conexão em rede cria a necessidade de que o sujeito, para ter acesso aos demais integrantes da rede, mantenha-se também acessível. Ainda, para o êxito de alguns programas, como a política de governo eletrônico, proporcionar as condições mínimas para que o maior número possível de pessoas possa se tornar um parceiro do Estado, controlando, regulando ações de cunho mais amplo e investindo na promoção da ID na educação, parece se constituir em uma ação de base e que atinge um grande número de sujeitos. Afinal, todos devem passar pela escola, desde o mais cedo possível.

Assim, compreende-se que muito mais do que um recurso didático, a conexão em rede e a disponibilidade para acessar e ser acessado funcionam como ferramentas por meio das quais os escolares podem ampliar suas redes de amizades, suas possibilidades de participação, de consumo, de competição e de concorrência. Nas palavras de Moraes e Veiga-Neto (2008, p. 6), "a interconexão planetária dos computadores em redes [...] tende a tornar-se a principal infraestrutura de produção, transação e gerenciamento econômicos na Contemporaneidade". Em síntese, importa criar as possibilidades para que o maior número possível de pessoas possa estar conectado e disponível para acessar e ser acessado. As ferramentas digitais se constituem em potentes instrumentos que podem fortalecer o governamento dos sujeitos e a produção de subjetividades, favorecendo com isso o desenvolvimento de um tipo de governamentalidade constituída pelo neoliberalismo. $\mathrm{O}$ incentivo à conexão em rede e à disponibilidade para acessar e ser acessado, atrelados ao desejo pela internet, possibilitam o estreitamento dos laços entre a gestão pública e os sujeitos, criando as condições de possibilidade para que estes se tornem parceiros do Estado no que diz respeito à condução das condutas de si mesmos e dos outros, conforme requer, por exemplo, a política de governo eletrônico. Entende-se, então, que 
uma outra forma de governamentalidade é produzida a partir das três ações que se elencou e que são mobilizadas por meio da promoção da ID na educação. De acordo com Lopes e Fabris (2013, p. 24, grifos das autoras),

práticas de governamento e de subjetivação [...] são modificadas e/ou deslocadas de foco fazendo emergir outras formas de governamentalidade. Dadas as contingências políticas, sociais, econômicas, educacionais, etc. enfrentadas respeitando recortes temporais e espaciais. Se entendermos que as contingências determinam as formas de vida, também entenderemos que elas determinam as formas de Governo.

A conexão em rede e a disponibilidade para acessar e ser acessado são estratégias que, atreladas à educação em todos os espaços, não apenas criam as condições para que outros tipos de práticas de governamento sejam exercidas - a condução das condutas parece estar cada vez mais ligada ao uso das TD - mas também produzem outros tipos de subjetividade. A promoção da ID na educação importância, por meio do incentivo à educação em todos os espaços, fortalecem a disseminação da conexão em rede e da disponibilidade para acessar e ser acessado. (frse truncada) Esses investimentos estão implicados com a constituição de empresários de si mesmos e, mais do que isso, produzem nesses sujeitos a necessidade de que seja desenvolvido outros tipos de comportamentos, fundamentais para o desenvolvimento desse tipo de governamentalidade que opera imbricada ao uso das TDs. Compreende-se que a acessibilidade é, portanto, o ponto fundamental de interesse da governamentalidade atual. Importa que se elucidem os sentidos que a palavra acessibilidade assume nesse contexto. Essa palavra é formada por acesso mais o sufixo idade, que significa condição. Na linguagem da informática, acesso está relacionado à capacidade de efetuar uma comunicação por meio de um dispositivo, para receber ou enviar dados, ou ainda à capacidade para se conectar à internet. Dessa forma, a acessibilidade, nesse caso, está relacionada à condição de ter acesso, ou seja, de se conectar à internet e, por meio dela, enviar e receber dados e estar acessível/ disponível para ser acessado. Por esse viés, sabe-se que ao Homo æeconomicus, na atualidade, é preciso agregar a habilidade da acessibilidade, para fazer referência à sua capacidade e à disponibilidade para acessar e manterse acessível. Em outras palavras, o sujeito empresário de si mesmo, na atualidade, é o Homo oeconomicus accessibilis. Este, além de assumir a responsabilidade pelo direcionamento das condutas de si e dos outros, deve também desenvolver condições para se manter conectado, disponível para acessar e ser acessado e, assim, cada vez mais disponível para ser capturável e conduzido.
Condição que ocorre na medida em que ele aprenda e dissemine a necessidade de que cada um assuma a importância de fazer investimentos em si mesmo; que aproveite as oportunidades que são oferecidas pelo Estado para desenvolver a educação em todos os espaços; que desenvolva habilidades como criatividade, autonomia, cooperação, comunicação; e que aumente o seu potencial de empregabilidade.

\section{CONSIDERAÇõES FINAIS}

Neste artigo, mais do que festejar a inserção de computadores, laptops, tablets, ou de outros recursos digitais nas escolas públicas, bem como mais do que exaltar as muitas práticas pedagógicas inovadores que são criadas a partir do acesso aos computares e, principalmente, a internet, a intenção foi problematizar a forma como está sendo propagada, por meio dos programas voltados para a ID na educação pública, a utilização de tais recursos. Entende-se que a inserção de TD na educação, com infraestrutura adequada e atualizada e com preparação do corpo docente para utilização produtiva das ferramentas digitais e da internet, é de fundamental importância para a qualificação do processo de ensino e de aprendizagem. De toda forma, as análises que se empreendeu sobre os materiais de pesquisa demonstraram que, mais do que qualificar o ensino e a aprendizagem, tais programas mobilizam discursos em prol de uma racionalidade política cuja lógica está pautada no mercado.

Concluindo, muito mais do que promover a efetiva ID daqueles sujeitos considerados em condição de risco social, o que os discursos que reverberam a promoção da ID na educação demonstram é a necessidade, por parte do Estado, de manter esses sujeitos sob a sua vigilância e conceder a eles condições, mesmo que mínimas, de participação nos modos de viver constituídos a partir da racionalidade neoliberal. Faz-se essa afirmação embasada nas três ações principais que foram mobilizadas por meio da promoção da ID na educação: a educação em todos os espaços, a conexão em rede e a disponibilidade para acessar e ser acessado. Por meio dessas ações que são operacionalizadas conjuntamente entre si e também amparadas em outras, como a distribuição de computadores, a capacitação de recursos humanos para o uso das TD e o desejo pela internet -, são feitos investimentos na constituição de um outro tipo de sujeito, qual seja, o Homo œconomicus accessibilis. Este, além de se responsabilizar por transformar a si mesmo em uma empresa, também desenvolve o desejo de estar conectado e assume para si a necessidade de se manter disponível para acessar e ser acessado. Dessa forma, mais do que exercer sua liberdade de escolha e desonerar o Estado pois é esperado que esse sujeito desenvolva as condições 
mínimas de empregabilidade para se responsabilizar pelo seu sustento -, ele amplia as suas chances de participação, consumindo e assim movimentando o mercado, e também as possibilidades de ser vigiado, capturado e regulado. Tal como preconiza a política de governo eletrônico, que dissemina ações como o Prouca, a participação da população é fundamental para a boa gestão do Estado.

\section{REFERÊNCIAS}

BALL, Stephen. Aprendizagem ao longo da vida, subjetividade e a sociedade totalmente pedagogizada. Educação, Porto Alegre, v. 36, n. 2, p. 144-155, 2013.

BARRETO, Raquel Goulart. A recontextualização das tecnologias da informação e da comunicação na formação e no trabalho docente. Educação \& Sociedade, Campinas, v. 33, n. 121 , p. $985-1002$, out.-dez. 2012. http://dx.doi.org/10.1590/ S0101-73302012000400004

BRASIL. Ministério do Planejamento, Orçamento e Gestão. Governo Eletrônico. Disponível em: <http://www.governo eletronico.gov.br/>. Acesso em: 07 dez. 2012.

CORRÊA, Rômulo de Amorim. A construção social dos programas públicos de inclusão digital. 2007. $168 \mathrm{f}$. Dissertação (Mestrado em Sociologia) - Instituto de Ciências Sociais, Universidade de Brasília, Brasília, 2007.

FAGUNDES, Léa da Cruz; SATO, Luciane Sayuri; MAÇADA, Débora Laurino. Aprendizes do futuro: as inovações começaram. São Paulo: USP, 1999 (Coleção Informática para a Mudança na Educação).

FOUCAULT, Michel. Segurança, território, população. São Paulo: Martins fontes, 2008a.

FOUCAULT, Michel. O nascimento da biopolítica. São Paulo: Martins fontes, 2008b.

KAMPFF, Adriana Justin Cerveira. Tecnologias da informação e comunicação na educação. Curitiba: IESDE Brasil, 2009.

LAGASNERIE, Geoffrey de. A última lição de Foucault. São Paulo: Três Estrelas, 2013.

LOPES, Maura Corcini. Norma, inclusão e governamentalidade neoliberal. In: CASTELO BRANCO, Guilherme; VEIGANETO, Alfredo (Org.). Foucault: filosofia \& política. Belo Horizonte: Autêntica, 2011.

LOPES, Maura Corcini; FABRIS, Eli Henn. Inclusão \& educação. Belo Horizonte: Autêntica, 2013.

LOPES, Maura Corcini; RECH, Tatiana Luíza. Inclusão, biopolítica, educação. Educação. Porto Alegre, v. 36, n. 2, p. 201-219, 2013.

LOPES, Maura Corcini; LOCKMANN, Kamila; HATTGE, Morgana Domênica; KLAUS, Viviane. Inclusão e Biopolítica. Cadernos IHU Ideias, v. 1, p. 3-36, 2010.

MEDEIROS, Paulo Henrique Ramos. Governo eletrônico do Brasil: aspectos institucionais e reflexos na governança. 2004. 315 f. Dissertação (Mestrado em Administração) - Faculdade de Economia, Administração, Contabilidade e Ciência da Informação e Documentação, Universidade de Brasília, Brasília, 2004.

MORAES, Antônio Luiz de; VEIGA-NETO, Alfredo. Disciplina e controle na escola: do aluno dócil ao aluno flexível. In: COLÓQUIO LUSO-BRASILEIRO SOBRE QUESTÕES CURRICULARES, 4., 2008, Florianópolis. Anais do IV Colóquio Luso-Brasileiro sobre Questões Curriculares. Florianópolis: UFSC/NUP, 2008.

NOGUERA-RAMIREZ, Carlos Ernesto. Pedagogia e governamentalidade: ou da modernidade educativa como uma sociedade educativa. Belo Horizonte: Autêntica, 2011.

PROGRAMA NACIONAL DE INFORMÁTICA EDUCATIVA - PRONINFE. Documento orientador. Brasília: Ministério da Educação e do Desporto, 1989.

PROGRAMA NACIONAL DE INFORMÁTICA NA EDUCAÇÃO - PROINFO. Diretrizes. Brasília: Ministério da Educação e do Desporto, 1997.

PROGRAMA UM COMPUTADOR POR ALUNO-PROUCA. Manual. Disponível em: <www.uca.gov.br/institucional// dowloads/manual_eletronico.pdf $>$. Acesso em: 04 dez. 2010a.

PROGRAMAUM COMPUTADOR POR ALUNO-PROUCA. Cartilha Projeto UCA. Cartilhas Projeto UCA: Redes sem fio, 2010b.

PROGRAMAUM COMPUTADOR POR ALUNO - PROUCA. Resolução/FNDE/CD/n ${ }^{\circ} 17$ de 10 de junho de 2010c.

SARAIVA, Karla; VEIGA-NETO, Alfredo. Modernidade líquida, capitalismo cognitivo e educação contemporânea. Revista Educação e Realidade, Porto Alegre, v. 1, n. 1, p. 187-201, Maio/Ago. 2009.

SENNETT, Richard. A corrosão do caráter: consequências pessoais do trabalho no novo capitalismo. Rio de Janeiro: Record, 2012.

SIBILIA, Paula. Redes ou paredes: a escola em tempos de dispersão. Rio de Janeiro: Contraponto, 2012.

VALENTE, José Armando. A escola como geradora e gestora de conhecimento: o papel das tecnologias de informação e comunicação. In: GUEVARA, Arnoldo José de Hoyos; ROSINI, Alessandro Marco (Org.). Tecnologias emergentes: organizações e educação. São Paulo: Cengage Learning, 2008.

VALENTE, José Armando. Informática na educação no Brasil. In: VALENTE, José Armando (Org.). O computador na sociedade do conhecimento. São Paulo: USP, 1999a. (Coleção informática para a mudança na educação)

VALENTE, José Armando. Mudanças na sociedade, mudanças na educação: o fazer e o compreender. In: VALENTE, José Armando (Org.). O computador na sociedade do conhecimento. São Paulo: USP, 1999b. (Coleção informática para a mudança na educação)

\section{Nota}

1 Entre tais grupos, citam-se o G-20, fundado em 1999; a Organização das Nações Unidas (ONU), fundada em 1946; a Organização para a Cooperação e Desenvolvimento Econômico (Ocde), criada em 1961. Neste último, o Brasil, embora não seja membro, participa do programa de engajamento ampliado que lhe permite fazer parte de Comitês da Organização www.fazenda.gov.br. O G-20 foi criado em 2003, em uma conferência da Organização Mundial do Comércio (OMC), realizada em Cancun. A OMC é responsável pela regulação do comércio mundial. $\mathrm{Na}$ atualidade, o G-20 é composto por 24 países, dentre eles, o Brasil.

Artigo recebido em setembro 2015.

Aprovado em dezembro 2015. 